\title{
DEVELOPMENT OF ADHESION AND ADHESION-WELDING TECHNOLOGY FOR REPAIR OF BEARING SEATS FOR EXTENSION OF SERVICE LIFE OF CASING PARTS OF POWER EQUIPMENT*
}

\author{
Yu.S. VASILEV, N.I. OLEJNIK and L.S. PARSHUTINA \\ E.O. Paton Electric Welding Institute, NASU \\ 11 Kazimir Malevich Str., 03680, Kiev, Ukraine. E-mail: office@paton.kiev.ua
}

\begin{abstract}
The analysis of physical and mechanical factors determining the service life of bearing units was carried out. The adhesion and adhesion-welding technologies for restoration of bearing seats in the supports of heavily loaded gears were developed. The compositions of repair composite material based on adhesive «Koutex» and the optimal modes of stage-by-stage deposition of coupling, filling and finishing coating layers were selected. The limit values of rheological characteristics of the adhesive compositions for formation of adhesion-welding repair joint were established. 4 Ref., 7 Figures.
\end{abstract}

K e y w or d s : repair technology, bearing unit, adhesion-welding technology, repair adhesive compositions, reducer

In Ukraine a large number of industrial equipment is operated, which has already worked out the service life specified by the manufacturer. The high degree of wear of geometrical parameters, the presence of fatigue and corrosion damages requires a large amount of repair works. The most common defect of casing parts wear is the wear of bearing seat surfaces. The restoration of mass casing parts is economically rational because it can significantly reduce the consumption of spare parts for repair and provide the necessary longevity of assembly units of the machines.

At the present time, a sufficient experience on repair of bearing units in the different-purpose structures was gained, which takes into account the operating modes and conditions of the equipment service, reliability and long life of bearings, convenience and easy maintenance during the operation process. The methods for restoration of worn-out surfaces on the basis of welding, spraying and surfacing using metal materials and powders have been widely used at the large specialized enterprises, where high-precision equipment for machining of bearing seats is applied to provide parallelism of axes and center-to-center distances. The application of welding and subsequent machining significantly increase the volume of accompanying works associated with disassembly and subsequent assembly of equipment elements, including overhead costs for transportation of disassembled equipment to repair and production sites. Therefore, development of effective repair and restoration technology of worn-out and damaged units of industrial equipment directly under the operation conditions or at the repair site is an urgent problem.

The use of polymeric materials greatly simplifies the technology for restoration of seats and increases the service life of rolling bearings due to redistribution of external load between the rolling elements [1]. In repair works of industrial equipment the highly filled metal-polymeric adhesive compositions (multi-metals) have been widely applied, and the technology was called «cold molecular welding». These composite materials (as compared with pure polymers) possess a high rigidity, strength and vibration resistance, heat resistance, dimensional stability and decreased gas and water permeability. The combining of technological welding and adhesion processes while using the metal-polymer compositions can improve rigid and strength properties of metal structures without reduction in operational loads.

The aim the research work was to develop adhesion and adhesion-welding technologies for repair of bearing units of power equipment at the place of oper-

\footnotetext{
*Based on materials of the work performed under purpose-oriented integrated program of the NAS of Ukraine «Problems of residual life and safe operation of structures, constructions and machines» (2013-2015).
} 
ation on the basis of domestic metal-adhesive compositions produced according to prescription modification of industrially produced polymeric matrices.

Basing upon the experience of design and service of metal rolling bearings the character of mating the bearing rings with the shaft and casings was determined, which depends on the type of their loading, i.e. circulating or local one [2]. The circulative-loaded rings should be joined with the mating part immovably. The presence of gap between the circulation loaded ring and the part coupled with it results in slipping of the ring relatively to the seat, that results in beading and wear of the shaft neck or casing, usually manufactured of softer metal than material of the bearing ring. On the contrary, a movable joining of locally loaded rings with the coupled parts provides the presence of gap or slight tightness between the ring and the seat, that under the action of shocks and vibrations allows the ring to slip slowly relatively to its seat, and in the operation instead of limited area the entire race of the ring is involved. Such a method of mounting the locally loaded rings greatly increases the service life of bearing, because otherwise wear of the ring race occurs at only one of its areas.

In accordance with the character of mating of bearings ring with the casing and taking into account the volume of wear of seat holes, the following repair methods of bearing units using the adhesive composite materials (ACM) were investigated:

1. Pasting-in the bearing rings into the seat with formation of fixed joint.

2. Formation of the seat holes of nominal size in the casing part with formation of minimum gap or small tightness.

It is recommended to perform pasting-in the bearings during wear of up to $0.25 \mathrm{~mm}$ using the fluid

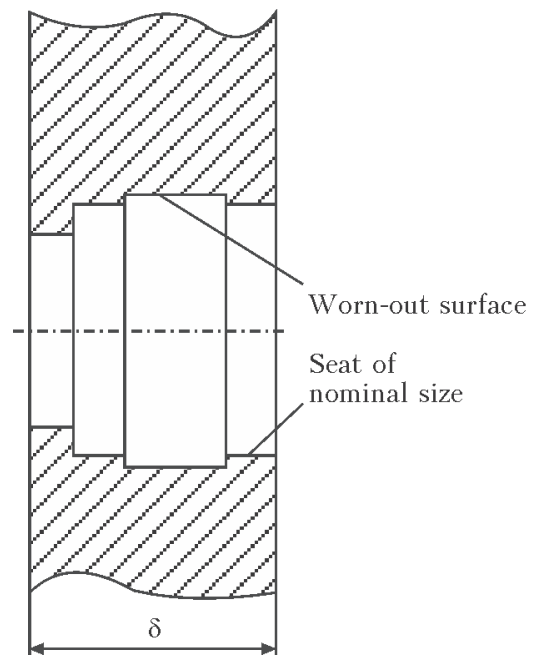

Figure 1. Restoration of bearing seats using ACM [3] anaerobic adhesive composites such as Anaterm and Unigerm (Russia), Loctite (US), Permabond (Great Britain) [1]. The principle of this method is that the process of restoration of the seat assembly is combined with bearing assembly operation, resulting in fixed joint of the bearing and the shaft (casing) which is many times superior as to its strength characteristics which in such cases is recommended for tight seating. It reliably protects bearing rings against slipping, eliminates fretting corrosion and provides a more reliable unit operation. At the same time, pasting-in unlike tight seating, does not result in arising stresses and deformations of bearing rings, that also contributes to a more reliable operation.

As an offer for substitution of imported foreign anaerobic materials we carried out the investigation on restoration of bearing units using the domestic adhesive compositions on epoxy and polyurethane polymer matrices. As the most technological and repairable adhesive composition «Koutex» was determined, which is the joint development of the Institute of High-Molecular Compounds (NASU) and Production Group «Diver». The composition represents a fluid two-package adhesive system (base + solidifier in ratio of 1:1) possessing a high adhesion to wetted and oily surfaces. The process of formation of repair joints consists in preliminary mechanical-chemical treatment of seats, deposition of thin layer of adhesive composition on the outer surface of the outer bearing ring and assembly of the bearing unit.

For repair of bearing units with wear of not more than $1 \mathrm{~mm}$, thixotropic adhesive composition «Koutex» is used, and the desired accuracy of assembly is endured by means of devices for fixing the parts in specific position for the period of solidifying. Otherwise, under the action of gravity the adhesive is ex-

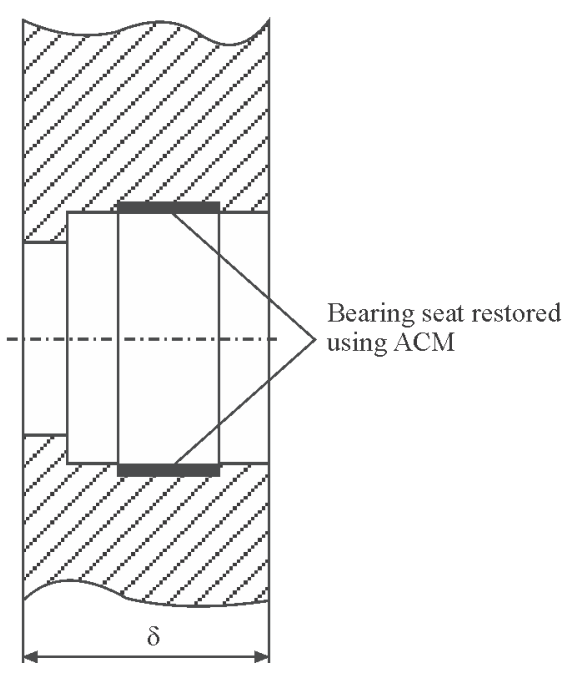


truded and the coaxiality of seat hole with bearing shaft is violated.

The repair of bearing units in the large-sized reducers of the power equipment consists in restoration of geometry of support bearing surfaces using ACM of different degrees of filling with inorganic particles. The pasty ACM is excessively applied on the place of wear and treated to the nominal size after solidification (Figure 1) [3]. The ACM interlayer between the outer bearing ring and the seating ring of the reducer casing is deformed under the action of external load, providing its rational distribution between the rotation bodies. In work [4] the optimal physical and mechanical characteristics of the polymer layer were determined depending on acting load and gap between the ring and the seat.

The necessary requirement to the applied ACM is providing the sufficient level of technological (initial) strength of adhesive-bonded joints in 30-60 min after deposition. This provides a significant reduction of labor intensity of the technological adhesion process due to possibility of carrying out the subsequent operations until the repair is fully completed. Within that period the adhesives with a long viability do not gain technological strength, that increases the repair period and duration of equipment downtime. Therefore, to develop the adhesion and adhesion-welding repair technologies of bearing units the investigations on improvement of adhesive compositions were carried out to develop the repair materials with the required level of rheological characteristics and viability.

In order to specify the chemical composition and quantitative content of components of the repair adhesive compositions (RAC) the analysis of investigations of materials of «Durmetall» (Switzerland) and «Chester Molecular» (USA), similar according to their purpose, was carried out. The results showed that the polymer base of the chosen materials is aromatic epoxy resin, which is confirmed by the presence of absorption peaks in the range of $2900 \mathrm{~cm}^{-1}$ (aromatic rings) and in the range of $830 \mathrm{~cm}^{-1}$ (epoxy groups). This conclusion is correlated also with the analysis of the mass-spectra having lines of molecular mass of 43 (epoxy group) and 94 (benzene ring). The solidifiers can be classified as anhydride (absorption bands of 1513 and $1718 \mathrm{~cm}^{-1}$ ) or oxide ones with the following rearrangement into amine groups at the presence of catalyst $\mathrm{PCl}$. This is confirmed by the presence of $\mathrm{HCN}$ remnants with molecular mass of 27 according to mass-spectrum and the band of $812 \mathrm{~cm}^{-1}$ according to IR-spectrum. The mass spectroscopy of the acti- vator of accelerated type shows the presence of line with molecular mass of 19 indicating that the catalyst is a complex of trifluoride boron with ether. The investigations carried out using the method of pyrolysis showed a high filling with inorganic particles ranging from 5 to $150 \mu \mathrm{m}$.

The revealed materials science regularities for creation of dispersion strengthened polymer composite materials formed the basis for the development of RAC on the base of domestic adhesive polymer matrix «Koutex» and solidifying systems like UP-583, UP-0633M and L-19, which is also an active plasticizer possessing the properties of surface-active agents. The investigations of RAC filling processes were carried out with introduction of particles of $\mathrm{Ti}$, $\mathrm{Fe}, \mathrm{Cr}, \mathrm{Zn}$ oxides, iron powders, quartz as well as particles of scaly form on the basis of basalt.

The interaction of the polymer matrix with amine solidifiers at the presence of the mentioned oxides was studied using the method of differential thermal analysis (DTA). It was established that all the used metal oxides influence the solidifying process of epoxy oligomer. At the same time, some shifting of temperature of the reaction beginning and the temperatures of maximum peak of DTA curve to the region of lower values is fixed as compared to the unfilled composition. Chromium oxide has the opposite effect. At the introduction of dispersed particles the exothermic effect is increased in the following order: $\mathrm{Cr}_{2} \mathrm{O}_{3} \rightarrow$ pure composition $\rightarrow \mathrm{Fe}_{2} \mathrm{O}_{3}>\mathrm{ZnO} \rightarrow \mathrm{TiO}_{2}$. At the introduction of oxides in epoxy composition the decrease in activation energy of the solidifying process is observed. The given data indicate the catalytic activity of Ti, Fe, $\mathrm{Zn}$ oxides and the inhibitory effect of $\mathrm{Cr}_{2} \mathrm{O}_{3}$ on the solidification process of epoxyamine compositions. In order to reduce the cost of consumables the quartz powder was used in form of particles of up to $200 \mu \mathrm{m}$ size.

It is known that introduction of highly dispersed particles of less than $1 \mu \mathrm{m}$ into polymer matrix leads to formation of chain structures, clusters and aggregates. In the process of multifraction filling the highly dispersed particles are filling the «free» volume between the larger fractions, increasing the degree of packing and strength values. The RAC strengthening was carried out by introducing ultra-dispersed powder (UDP) of silicon carbide (SiC) with the particle size of $0.03-0.2 \mu \mathrm{m}$ and specific surface of about $20 \mathrm{~m}^{2} / \mathrm{g}$. At the introduction of UDP with volumetric fraction of about $0.1-0.20$ the strengthening effect of the filler is revealed in increase of the surface energy of de- 


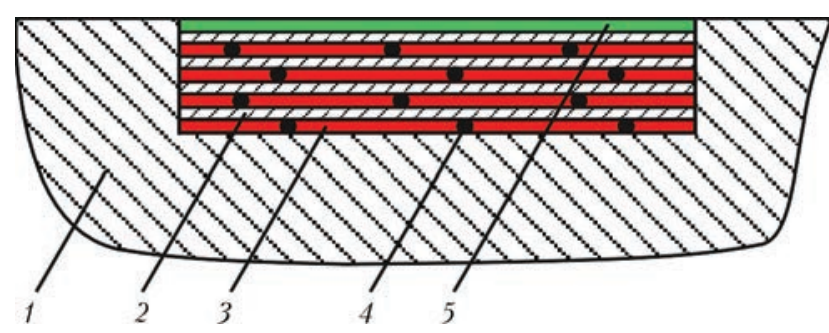

Figure 2. Adhesion-welding method for restoration of bearing seat in casing part: 1 - support; 2 - multilayer of sheet steel $05 \mathrm{kp}$ (rimmed); 3 - filler of interlayer space (anaerobic sealant); 4 - weld spot; 5 - finishing layer of composite

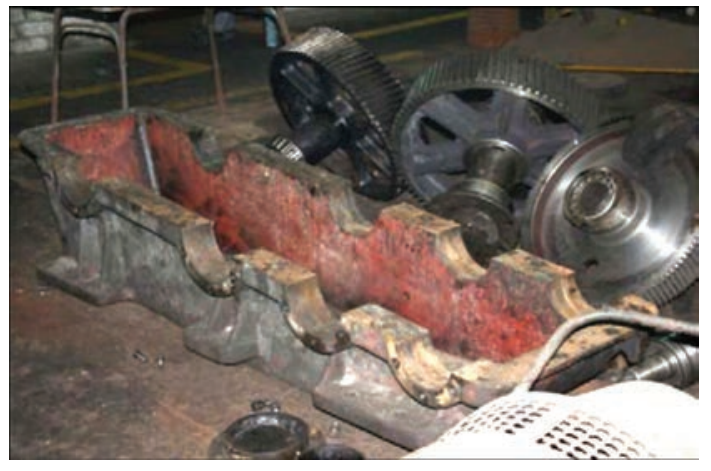

Figure 3. Casing of reducer RLKU-250M

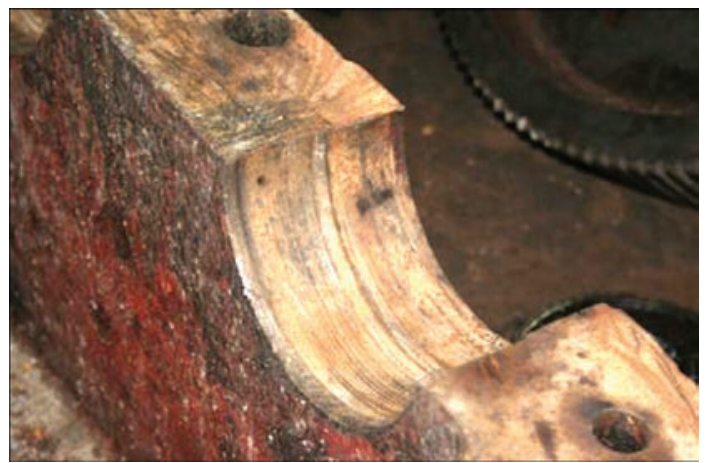

Figure 4. Wear of bearings seats

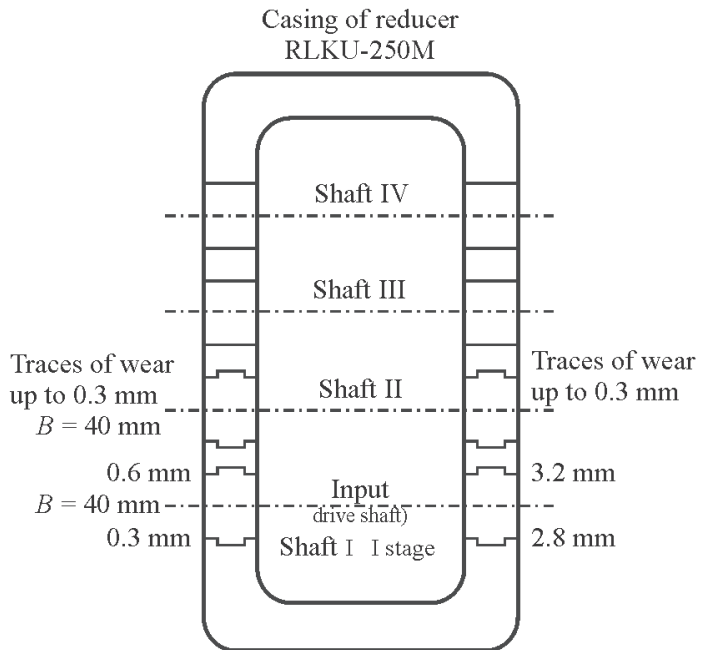

Traces of wear are given for bearings seats of the outer frame. Width of seats is up to $B=40 \mathrm{~mm}$

Figure 5. Map of location and sizes of defects subjected to repair using RAC struction and tensile strength. In the composition an infinite volumetric cluster of UDP particle chains appears connected with the coarse-dispersed particles through the film matrix interlayers, and forming the frame representing a spatial network. During loading such a frame is deformed and its cells are distorted either stretching or compressing depending on direction of the applied load.

We developed the adhesion technology for restoration of bearing seat surfaces in the reducer casing based on the formation of three-layer repair composite coating. The first layer is the finishing agent (primer) with high adhesive capacity to the restorable support surface (RAC-1). The second is filling one with the high strength and damping characteristics (RAC-2). The third is finishing one providing the maximum value of the actual contact (RAC-3).

To repair the heavily loaded bearing units and compensate the significant wear of bearing surfaces, we proposed the adhesion-welding design of repair rolling bearing seat in the casing of large-sized reducer in order to improve the bearing capacity and bending rigidity of so-called «filling layer» (Figure 2).

The repair structure represents multilayer, composed of set of thin-sheet metal plates of $0.1-0.5 \mathrm{~mm}$ thickness joined by weld spots and adhesive interlayers. The contact surface with bearing is formed of the elastic adhesive composite material (see Figure 2).

The practicing of technological methods for repair of power equipment using the experimental RAC was carried out at the enterprises of Donetsk Fuel-Energy Company DTEK. As an object of investigations the repair of large-sized cylindrical reducer RLKU-250M (Figure 3) was selected. As a result of inspection of

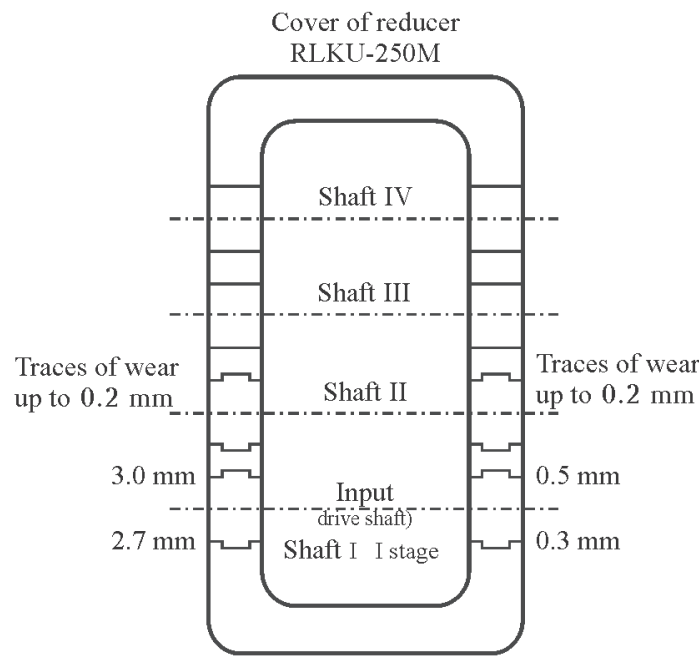




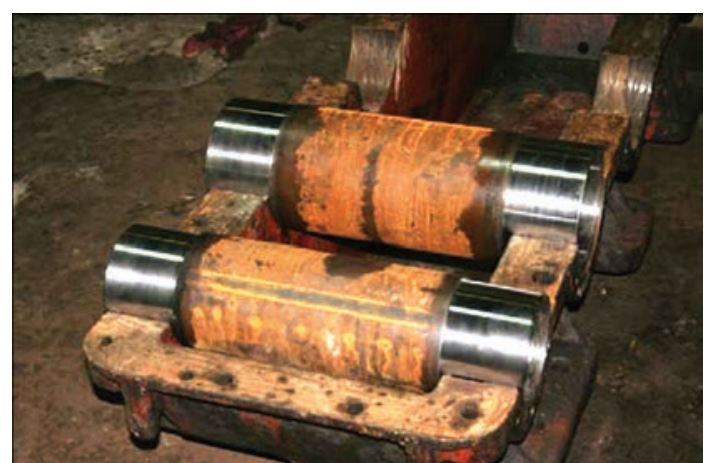

Figure 6. Installation of false shafts on bearing seats

the reducer, the places of wear were revealed and the sizes of defects were measured (Figures 4 and 5). The checking of ovality and conicity of seats, not subjected to wear, using the false shaft (Figure 6) demonstrated their compliance with the dimensions and tolerances specified in the working drawings. The restoration of seat bearings (shafts I and II) was performed according to the technological regulations of reducer repair.

The final inspection of the restored bearing seats was performed by painting method using the false shafts (Figure 7).

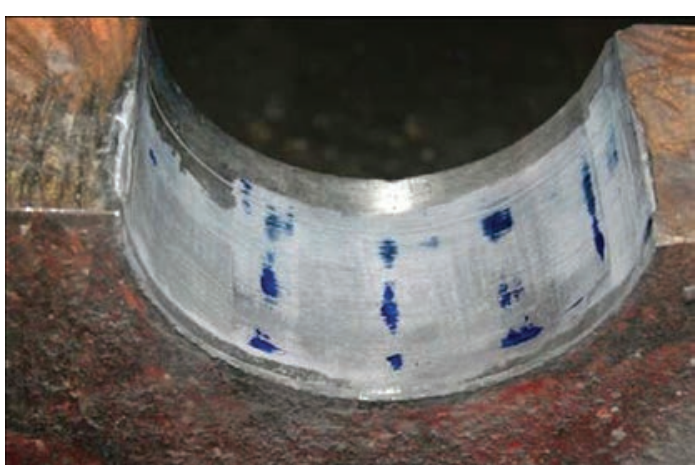

Figure 7. Control of accuracy of bearing seats restoration

After the industrial tests the repaired reducer is operated at the Pershotravnesky repair-mechanical plant since March 2014 until now.

1. Gryaznov, B.A., Bukhtiyarov, V.K., Kakuevitsky, V.A. et al. (2013) Application and strength of polymer materials in manufacturing and repair of machines and equipment. Kiev: IP3.

2. Perel, L.Ya. (1983) Rolling bearings: Calculation, design and maintenance of supports: Refer. book. Moscow: Mashinostroenie.

3. Goncharov, A.B., Tulinov, A.B., Odintsov, L.G. Method of diameter size reconstruction of drying cylinder of papermaking equipment. Pat. 2364487 UA. Publ. 20.08.2009.

4. Tulinov, A.B., Goncharov, A.B. (2003) New composite materials in repair production. Remont. Vosstanovlenie. Moderniz., 11, 46-49. 